\title{
New Perspectives in Tolerance Induction for Vascularized Composite Allotransplantation
}

\author{
Jeng-Yee Lin ${ }^{1}$ and Shuen-Kuei Liao ${ }^{2^{*}}$ \\ ${ }^{1}$ Division of Plastic Surgery, Department of Surgery, Taipei Medical University Hospital, and Medical College, Taipei Medical University, Taipei, Taiwan \\ ${ }^{2}$ Graduate Institute of Cancer Biology and Drug Discovery and Center of Excellence for Cancer Research, Taipei Medical University, Taipei, Taiwan
}

*Corresponding author: Shuen-Kuei Liao, Taipei Medical University, 250 Wu-Hsing St., Taipei 11031, Taiwan, Tel: +886-0912-753-715; E-mail: liaosk@h.tmu.edu.tw

Rec date: Apr 29, 2014; Acc date: Jun 11, 2014; Pub date: Jun 13, 2014

Copyright: ( 2014 Lin JY, et al. This is an open-access article distributed under the terms of the Creative Commons Attribution License, which permits unrestricted use, distribution, and reproduction in any medium, provided the original author and source are credited.

\begin{abstract}
Although transplantation of Vascularized Composite Allografts (VCA) has become a clinical reality, complications resulting from long-term immunosuppression remain major barriers to broader indication. Ideally, induction of tolerance has been considered the Holy Grail in both solid organ and VCA transplantation. Recent advances in immunomodulatory medication and cell-based therapy exploiting donor bone marrow (BM) cells, regulatory T cells (Tregs) and mesenchymal stem cells have opened exciting opportunities for tolerance induction in VCA transplantation. This mini-review focuses on current understanding of these drugs and cell-based immunomodulatory strategies and their role(s) in tolerance induction for VCA transplantation.
\end{abstract}

Keywords: Tolerance induction; Vascularized composite; Allograft; transplantation, Regulatoy T Cell; Mixed chimerism

\section{Introduction}

To date, clinical transplantations of a variety of vascularized composite allografts (VCA) including 23 faces, close to 85 upper extremities along with abdominal wall [1], total larynx [2], bone and joint [3], and tongue [4] have been performed in the past two decades with remarkable outcomes regarding graft survival and graft function. Immunosuppressive medication is widely used in current clinical practice to ensure immediate post-transplantation allograft function and survival. However, complications from long-term immunosuppression such as infection, malignancy, or metabolism disorders have made a wider clinical application of VCA transplantation not justifiable since VCA transplantation itself is not life-saving. In addition, acute rejection episodes and chronic graft rejection leading to graft loss have not been totally avoided with current immunosuppressive drugs. Therefore, tolerance induction would be an ideal solution to current problems facing solid organ or VCA transplantation. Two kinds of mechanism are responsible for maintaining tolerance in humans, namely, (i) the central tolerance which involves clonal deletion of allo-reactive lymphocytes in the thymus and (ii) the peripheral tolerance that takes place outside thymus leads to continued inhibition, anergy or deletion of alloreactive lymphocytes by regulatory $\mathrm{T}$ lymphocytes (Treg) [5]. A variety of protocols for tolerance induction are currently under extensive investigation. The protocols that mainly involve central tolerance mandate a certain degree of myeloablative irradiation in the host to allow engraftment of donor Bone Marrow (BM) cells after transplantation, which in turn induces tolerance to subsequent allotransplantaton and creates co-existence of both donor and host blood cells (hematopoietic chimerism). Creation of stable chimerism, though reliable in tolerance induction, can hardly be used routinely within clinical setting due to the requirement of host irradiation and the risk of Graft-Versus-Host Disease (GVHD). Therefore, paradigm shift occurred in methods of tolerance induction that depend more upon immunomodulation from Tregs. Recently developed immunomodulatory drugs, cell-based therapy, or both in combination have engaged a more important role from Tregs and have provided a new hope for tolerance induction in clinical VCA transplantation.

\section{Immunosuppressive Drugs}

The current immunosuppression protocols in clinical VCA transplantation are extrapolated from regimens used in solid organ transplantation [6], commencing with induction therapy with polyclonal antithymocyte globulins, or monoclonal antibody (mAb) (alemtuzumab, basiliximab), followed by triple-drug maintenance therapy (tacrolimus, mycophenolate mofetil, and steroid). Maintenance may be interspersed with rescue therapies if episodes of acute rejection occur. However, the experimental evidence suggests that these immunosuppressants do not induce tolerance by themselves $[7,8]$. Therefore, newer drugs have been developed to promote tolerogenic effect and reduce immunosuppressive dosage. Intriguingly, rapamycin and everolimus selectively facilitate expansion of human Tregs and preserve the immunosuppressive activity of Tregs in vitro, which in turn suppress donor reactive cells [9]. Mycophenolate mofetil when combined with 1a,25-dihydroxyvitamin D3 has been shown to increase Treg frequency and induce transplantation tolerance in a mouse experimental model [10]. A short-term (14-days) course of cyclosporine, a calcineurium inhibitor, in conjunction with IL-2/Fc fusion protein promotes tolerance by allowing exaggerated activationinduced cell death of effector $\mathrm{T}$ cells and at the same time enhancing allospecific immunoregulatory function of Tregs in a rodent experiment [11]. Additionally, manipulation of one or more of costimulation signals on T cells through CD154, CD28 and inducible T cell co-stimulator (ICOS) has a great potential in tolerance induction for VCA transplantation (Table 1). 


\begin{tabular}{|c|c|c|}
\hline Immunomodulatory drug & Protocol characteristics & Disadvantages, side effects or other remarks \\
\hline Rapamycin/everolimus & Immunosuppression, Treg expansion, clinically approved & Leukocytopenia, anemia, skin rash \\
\hline MMF+Vitamin D3 & Immunosuppression, Treg expansion, clinically approved & Leukocytopenia, anemia, skin rash \\
\hline Abatacept/Belatacept & $\begin{array}{l}\text { CTLA4-Ig fusion protein, inhibition of } \mathrm{T} \text { cell activation and } \\
\text { increase Treg; clinically approved }\end{array}$ & Post-transplantation, lymphoproliferative disorder \\
\hline Anti-CD154 & Blockade of CD154/CD40 costimulation, increase Treg, & Thromboembolism \\
\hline Anti-CD28 & $\begin{array}{l}\text { Blockade of CD28/CD80CD86 costimulation; increase } \\
\text { Teg; animal studies }\end{array}$ & \\
\hline Anti-CD40 & $\begin{array}{l}\text { Blockade of CD154/CD40 costimulation, increase Treg, } \\
\text { animal studies }\end{array}$ & \\
\hline Cell-based therapy & Protocol characteristics & Disadvantages, side effects or other remarks \\
\hline $\begin{array}{l}\text { Mixed hematopoietic } \\
\text { chimerism }\end{array}$ & $\begin{array}{l}\text { Induction of reliable tolerance, appplication only in } \\
\text { selected clinical cases where BMT is needed. }\end{array}$ & $\begin{array}{l}\text { Host conditioning with myeloablation is required for } \\
\text { stable chimerism; risk of GVHD. }\end{array}$ \\
\hline BM transfusion & $\begin{array}{l}\text { Reduction of immunosppression, animal studies and } \\
\text { preclinical trials }\end{array}$ & Unable to induce tolerance in humans \\
\hline Dendritic cells & Prolongation of allograft survival, animal studies & Unable to induce tolerance in humans \\
\hline Treg & Induction of tolerance to VCA in animal models & Unable to induce tolerance in humans \\
\hline Mesenchymal stem cells & Induction of tolerance in animal models & \\
\hline
\end{tabular}

Table 1: Therapeutic strategies for tolerance induction in VCA transplantation

Costimulatory blockade could lead to T cell inhibition, anergy, or deletion despite the successful interaction of $\mathrm{T}$ cell receptor with processed peptide-MHC complex, a step being a prerequisite for $\mathrm{T}$ cell activation. Abatacept and Belatacept (human CTLA4-Ig fusion protein) are two clinically approved drugs for prophylaxis of renal transplant rejection. They inhibit $\mathrm{T}$ cell response by competing with CD28, a costimulatory molecule, thereby decreasing IL-2 secretion and promoting expansion of Tregs. Other therapeutic strategies of costimulatory blockade under intensive investigations include antiCD28, anti-CD154, and anti-CD40 anibodies. These newly developed biological drugs hold promises in clinical VCA transplantation.

\section{Cell-based Therapy}

Mixed hematopoietic chimerism has been reliable for tolerance induction and long-term allograft survival [12-14]. However, this approach is limited in its clinical feasibility due to the requirement of host conditioning and the risk of GVHD. Clinically, a cell-based therapy using donor $\mathrm{BM}$ cell transfusion has been reported to minimize the maintenance of immunosuppression in both organ and upper extremity transplantations probably through a mechanism involving chimerism [15]. The approach with $\mathrm{BM}$ infusion either to induce hematopoietic chimerism or for the intensification of clonal exhaustion and deletion of allo-reactive $\mathrm{T}$ cells is encouraging and carries no risk of GVHD, since no host conditioning with irradiation is given. Recently, there was an emerging consensus that immunoregulation from Treg plays a critical role in dominant tolerance for organ transplantation [16,17]. Moreover, increased frequency of FoxP3+ Treg expression in the hand transplant has been demonstrated during rejection episodes which were very well responsive to rescue therapy [18]. In addition, our recent study showed that co-treatment with Tregs and costimulatory blockade without recipient conditioning led to long-term donor-specific tolerance to VCA in a rat model [19]. Strikingly, mechanisms involving both deletion of allo-reactive effector $\mathrm{T}$ cells and regulation by Tregs play an important role for tolerance induction of VCA in this rat model. Therefore, novel insights lead to the concept that a balance between allo-reactive cytopathic T-cell and allo-specific Treg is critical in preventing graft rejection with concomitant promotion of graft tolerance [20-23]. Shifting the balance toward enhancing the allospecific Treg function will promote allograft tolerance and its concept can be used as a strategy for tolerance induction. Although both deletion and regulation play important roles in allograft acceptance, quantitative details for each mechanism may differ from one model to another [24]. Thus, tools that can effectively expand allo-specific Tregs are currently under extensive exploration [25-27]. One of the most actively investigated approaches is donor specific transfusion (DST) and anti-CD154 mAb treatment [12,28-30]. Although deletional mechanism is not complete in regimens involving DST plus costimulatory blockade (e.g. anti-CD154 mAb), which still rely largely upon immunoregulation from Tregs to maintain allograft survival, it seems to lower the threshold for effective Treg function [24]. Other potential cell-based therapies (Table 1) currently under extensive investigation include tolerogenic dendritic cells and adipose-derived mesenchymal stem cells [31-33]. Dendritic cells are antigen presenting cells, the majority of which are functionally immature and incapable of presenting donor antigen to $\mathrm{T}$ cells efficiently, therefore leading to disabled T cell activation [34]. Mesenchymal stem cells of the recipient origin could provide the convenience, elicit immense tolerogenic effects and ameliorate GVHD after hematopoietic stem cell transplantation [35,36]. In addition, mesenchymal stem cells promote neurogenesis and facilitate recovery of VCA (as in hand transplant) function following transplantation. Therefore, fine-tuning of the tolerance induction protocol using recipients' mesenchymal stem cells 
for its optimization potentially could be an appealing approach in tolerance induction for VCA transplantation.

\section{Discussion}

Interestingly, VCA transplantation has been found to have less immunogenicity than transplantation of each component itself, especially the skin component which in the past is considered the most immunogenic one. One possible explanation is the unique feature of VCA such as arm or bone and joint that may naturally involve vascularized transplantation of BM cells along with VCA transplantation, and therefore provide a constant source of donor BM cells to facilitate tolerance induction through a mechanism not yet fully understood. The mechanism involved may have been associated with macro-, mixed or micro-chimerism. In fact, use of maintenance immunosuppression in hand transplantation has resulted in $100 \%$ patients and graft survival in 1 year post transplantation, an outcome that has not been able to achieve in any other field of transplantation [37].

The clinical use of CLTA4-Ig (Abatacept and Belatacept) is associated with post-transplantational lymphoproliferative disorder and failure to prevent rejection. Also, clinical trial of anti-CD154 mAb developed thromboembolic complications due to activated platelet expressing CD154 [38]. Therefore, development of new costimulation blockade drugs that prove safe and more efficacious is warranted.

A growing body of evidence has shown that use of costimulation blockade or Treg leads to tolerance induction and long term allograft acceptance in rodent models. However, no evidence has been shown so far that these new immunomodulatory drugs or Tregs themselves, when used alone, can induce tolerance in humans. These differences may partially be accounted for the increased complexity of higher vertebrae immune system and the increased diversity of preexisting immunity due to exposure of environmental antigens [38,39].

These data present the rationale for combination therapy using both deletional and regulatory mechanisms for tolerance induction while reducing immunosuppression regimen after VCA transplantation. Nevertheless, combination of such a concept with high-dose multi-drug immunosuppression might be counterproductive because regulatory mechanisms require persistence of a certain degree of immune response to be successful in a clinical setting [40-42].

In conclusion, continued research on and implementation of novel immunomodulatory drugs together with these cell-based therapies can further help to reduce immunosuppression, induce immune tolerance, and optimize outcome of clinical VCA transplantation.

\section{Acknowledgements}

This work was supported in part by grants from Taipei Medical University Hospital (100-TMU-TMUH-11) and the Department of Health of Taiwan (DOH99-TD-111- 008).

\section{References}

1. Levi DM, Tzakis AG, Kato T, Madariaga J, Mittal NK, et al. (2003) Transplantation of the abdominal wall. Lancet 361: 2173-2176.

2. Strome M, Stein J, Esclamado R, Hicks D, Lorenz RR, et al. (2001) Laryngeal transplantation and 40-month follow-up. N Engl J Med 344: 1676-1679.
3. Guimberteau JC, Baudet J, Panconi B, Boileau R, Potaux L (1992) Human allotransplant of a digital flexion system vascularized on the ulnar pedicle: a preliminary report and 1-year follow-up of two cases. Plast Reconstr Surg 89: 1135-1147.

4. Kermer C, Watzinger F, Oeckher M (2008) Tongue transplantation: 10month follow-up. Transplantation 85: 654-655.

5. Sakaguchi S, Yamaguchi T, Nomura T, Ono M (2008) Regulatory T cells and immune tolerance. Cell 133: 775-787.

6. Barker JH, Francois CG, Frank JM, Maldonado C (2002) Composite tissue allotransplantation. Transplantation 73: 832-835.

7. Wagner SJ, Brennan DC (2012) Induction therapy in renal transplant recipients: how convincing is the current evidence? Drugs 72: 671-683.

8. Matthews JB, Ramos E, Bluestone JA (2003) Clinical trials of transplant tolerance: slow but steady progress. Am J Transplant 3: 794-803.

9. Battaglia M, Stabilini A, Roncarolo MG (2005) Rapamycin selectively expands CD4+CD25+FoxP3+ regulatory T cells. Blood 105: 4743-4748.

10. Adorini L, Giarratana N, Penna G (2004) Pharmacological induction of tolerogenic dendritic cells and regulatory $\mathrm{T}$ cells. Semin Immunol 16: 127-134.

11. Kang HG, Zhang D, Degauque N, Mariat C, Alexopoulos S, et al. (2007) Effects of cyclosporine on transplant tolerance: the role of IL-2. Am J Transplant 7: 1907-1916.

12. Ildstad ST, Sachs DH (1984) Reconstitution with syngeneic plus allogeneic or xenogeneic bone marrow leads to specific acceptance of allografts or xenografts. Nature 307: 168-170.

13. Sharabi Y, Sachs DH (1989) Mixed chimerism and permanent specific transplantation tolerance induced by a nonlethal preparative regimen. J Exp Med 169: 493-502.

14. Kawai T, Cosimi AB, Spitzer TR, Tolkoff-Rubin N, Suthanthiran M, et al. (2008) HLA-mismatched renal transplantation without maintenance immunosuppression. N Engl J Med 358: 353-361.

15. Schneeberger S, Gorantla VS, Brandacher G, Zeevi A, Demetris AJ, et al. (2013) Upper-extremity transplantation using a cell-based protocol to minimize immunosuppression. Ann Surg 257: 345-351.

16. Boros P, Bromberg JS (2009) Human FOXP3+ regulatory $\mathrm{T}$ cells in transplantation. Am J Transplant 9: 1719-1724.

17. Li L, Godfrey WR, Porter SB, Ge Y, June CH, et al. (2005) CD4+CD25+ regulatory T-cell lines from human cord blood have functional and molecular properties of T-cell anergy. Blood 106: 3068-3073.

18. Hautz T, Brandacher G, Zelger B, Müller HG, Lee AW, et al. (2009) Indoleamine 2,3-dioxygenase and foxp3 expression in skin rejection of human hand allografts. Transplant Proc 41: 509-512.

19. Lin JY, Tsai FC, Wallace CG, Huang WC, Wei FC, et al. (2012) Combined treatment with regulatory $\mathrm{T}$ cells and vascularized bone marrow transplantation creates mixed chimerism and induces donorspecific tolerance to vascularized composite allografts without cytoreductive conditioning. J Surg Res 178: 974-981.

20. Cohen JL, Trenado A, Vasey D, Klatzmann D, Salomon BL (2002) $\mathrm{CD} 4(+) \mathrm{CD} 25(+)$ immunoregulatory T Cells: new therapeutics for graftversus-host disease. J Exp Med 196: 401-406.

21. Kingsley CI, Karim M, Bushell AR, Wood KJ (2002) CD25+CD4+ regulatory T cells prevent graft rejection: CTLA-4- and IL-10-dependent immunoregulation of alloresponses. J Immunol 168: 1080-1086.

22. Cobbold S, Waldmann H (1998) Infectious tolerance. Curr Opin Immunol 10: 518-524.

23. Graca L, Cobbold SP, Waldmann H (2002) Identification of regulatory $\mathrm{T}$ cells in tolerated allografts. J Exp Med 195: 1641-1646.

24. Gorantla VS, Schneeberger S, Brandacher G, Sucher R, Zhang D, et al. (2010) T regulatory cells and transplantation tolerance. Transplant Rev (Orlando) 24: 147-159.

25. Hippen KL, Merkel SC, Schirm DK, Sieben CM, Sumstad D, et al. (2011) Massive ex vivo expansion of human natural regulatory T cells (T(regs)) with minimal loss of in vivo functional activity. Sci Transl Med 3: 83ra41. 
Citation: Lin JY, Liao SK (2014) New Perspectives in Tolerance Induction for Vascularized Composite Allotransplantation. Surgery Curr Res 4: 196. doi:10.4172/2161-1076.1000196

Page 4 of 4

26. Earle KE, Tang Q, Zhou X, Liu W, Zhu S, et al. (2005) In vitro expanded human CD4+CD25+ regulatory $\mathrm{T}$ cells suppress effector $\mathrm{T}$ cell proliferation. Clin Immunol 115: 3-9.

27. Jiang S, Tsang J, Game DS, Stevenson S, Lombardi G, et al. (2006) Generation and expansion of human CD4+ CD25+ regulatory T cells with indirect allospecificity: Potential reagents to promote donor-specific transplantation tolerance. Transplantation 82: 1738-1743.

28. Vincenti F, Blancho G, Durrbach A, Friend P, Grinyo J, et al. (2010) Fiveyear safety and efficacy of belatacept in renal transplantation. J Am Soc Nephrol 21: 1587-1596.

29. Kirk AD, Knechtle SJ, Sollinger HF, Vincenti G, Stecher S, et al. (2001) Preliminary results of the use of humanized anti-CD 154 in human renal allotransplantation. Am J Transplant. 1: S191.

30. Pirenne J, Kitade H, Kawai M, Koshiba T, Van Damme B, et al. (2005) Regulatory cells, TH1/TH2 unbalance, and antibody-induced chronic rejection in operational tolerance induced by donor-specific blood transfusion. Transplantation 79: S25-S27.

31. Belz GT, Heath WR, Carbone FR (2002) The role of dendritic cell subsets in selection between tolerance and immunity. Immunol Cell Biol 80: 463-468.

32. Barratt-Boyes SM, Thomson AW (2005) Dendritic cells: tools and targets for transplant tolerance. Am J Transplant 5: 2807-2813.

33. Pan H, Zhao K, Wang L, Zheng Y, Zhang G, et al. (2010) Mesenchymal stem cells enhance the induction of mixed chimerism and tolerance to rat hind-limb allografts after bone marrow transplantation. J Surg Res 160: 315-324.
34. Wilson NS, El-Sukkari D, Belz GT, Smith CM, Steptoe RJ, et al. (2003) Most lymphoid organ dendritic cell types are phenotypically and functionally immature. Blood 102: 2187-2194.

35. Le Blanc K, Frassoni F, Ball L, Locatelli F, Roelofs H, et al. (2008) Mesenchymal stem cells for treatment of steroid-resistant, severe, acute graft-versus-host disease: a phase II study. Lancet 371: 1579-1586.

36. Cheng HY, Ghetu N, Huang WC, WangYL, Wallace CG, et al. (2014) Syngeneic adipose-derived stem cells with short-term immunosuppression induce vascularized composite allotransplantation tolerance in rats. Cytotherapy 16: 369-380.

37. Lanzetta M, Petruzzo P, Dubernard JM, Margreiter R, Schuind F, et al. (2007) Second report (1998-2006) of the International Registry of Hand and Composite Tissue Transplantation. Transpl Immunol 18: 1-6.

38. Couzin J (2005) Drug discovery. Magnificent obsession. Science 307: 1712-1715.

39. Kirk AD (2003) Crossing the bridge: large animal models in translational transplantation research. Immunol Rev 196: 176-196.

40. Schneeberger S, Gorantla VS, Hautz T, Pulikkottil B, Margreiter R, et al. (2009) Immunosuppression and rejection in human hand transplantation. Transplant Proc 41: 472-475.

41. Starzl TE (2008) Immunosuppressive therapy and tolerance of organ allografts. N Engl J Med 358: 407-411.

42. Huang WC, Lin JY, Wallace CG, Wei FC, Liao SK (2012) Improving the safety of tolerance induction: chimerism and cellular co-treatment strategies applied to vascularized composite allografts. Clin Dev Immunol 2012: 107901. 